\title{
Milk quality - a future approach. From the dairy industry's point of view
}

\author{
H. Refsholt ${ }^{1}$, J. Brendehaug ${ }^{2}$, A.S. Biong ${ }^{3}$ and E. Selmer-Olsen ${ }^{3,4}$ \\ ${ }^{1}$ TINE BA, P.O. Box 25, N-0051 Oslo, Norway \\ ${ }^{2}$ TINE BA, P.O. Box 50, N-4358 Kleppe, Norway \\ ${ }^{3}$ TINE BA, P.O. Box 7, Kalbakken, N-0902 Oslo, Norway
}

\begin{abstract}
Historically, milk quality has been defined as product related quality. Lately, more focus has been given to production related quality and consumer demands. The quality of Norwegian milk is very high, and the Norwegian dairy breed, has achieved great recognition abroad. The Norwegian Food and Nutrition Policy goals state that food should be nutritionally adequate and safe, healthy and produced in a sustainable way. We will influence the nutritional quality through feeding and breeding, and study taste and qualities of milk and products made from this milk. We will also focus on naturally bioactive components, and milk products according to place of origin and season.
\end{abstract}

KEY WORDS: milk quality, challenges, consumer request, objectives for the future

\section{INTRODUCTION}

TINE BA is the country's leading supplier of food products and Norway's leading value generator. TINE BA is the sales and marketing organization for Norway's dairy cooperative and is responsible for product development, quality assurance, production and distribution planning, marketing and the export of TINE products.

The quality of the milk delivered by farms is vital as far as the end result is concerned. This is why TINE provides an extensive advisory service to its owners. Having our own advisory service which works to increase the profitability ofTINE's producers is important. The KSL Quality System for Agriculture documents how the production takes place and provides farmers with a management system for improving production operations. KSL is a tool that is linked to payments for raw

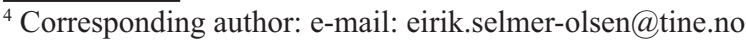


milk in order to improve the work done on quality throughout the entire value chain.

TINE Raw Materials is a separate division in TINE that is, from both an accounts and administrative point of view, separate from the rest of TINE. TINE Raw Materials' job is to purchase the milk from TINE's producers and sell it on to the dairy companies through the system of market regulation for milk, including TINE's industrial enterprises. The Norwegian Agricultural Authority (SLF) decides who can participate in the system of market regulation for milk.

2006 is the 125th anniversary of the dairy cooperative in Norway, and TINE is represented throughout the country with its 17.850 owners, around 5.350 employees, 52 dairy plants, and 6 plants for the production of other products than dairy products. The producers deliver approx. 1.450 billion litres of cow's milk and about 20 million litres of goat's milk every year. The group's turnover in 2005 was NOK 14.7 billion.

This presentation will focus on the challenges in the light of the dairy industry and TINE BA in particular. We will briefly mention the consumer and authority demands, present the milk quality status in Norway of today, and shed light on some of the goals of our research projects related to cow's milk quality.

\section{MILK QUALITY FROM THE DAIRY INDUSTRY'S POINT OF VIEW}

\section{Challenges facing the dairy industry in Norway}

Increasing globalization and reduced protective duties will cause more international trading also with food items. Norway has a high price level, which implies that our country represents an interesting market. A WTO agreement could pressure the price level and subsequently cause an increase in the import of goods. An increase in trade between the EU and Norway would cause the same.

What will then become the most important competitive conditions for the Norwegian dairy farming? Increasing commerce will probably intensify the consumer focus and a demand for more multiplicity. If we are to be competitive we will have to offer extra values like for instance different quality aspects. We will to a considerable extent have to develop further added value and uniqueness preferred by the consumer for the specific products.

The market for milk as beverage is expected to be particularly exposed for an increase in competition from abroad. This competition concerns UHT (Ultra High Temperature) milk, ESL (Extended Shelf Life) milk and fresh milk produced in our nearest neighbouring countries. The distribution of UHT milk is less cost demanding. We will probably experience an increased competition between fresh milk and different types of UHT products. Chances are that we will have to 
maintain and further develop the area of fresh milk. The main challenge will then be to obtain a high quality that will oust any possible import of UHT and fresh milk.

In the long run an increasing commerce may possibly necessitate multilateral legislation. Such legislation may facilitate the cross-border trade. When a tariff barrier is being gradually phased out, it is expected that a harmonization of legislation and regulations for labelling and labelled articles will become even more important. The situation today is that we already have a comprehensive common legislation within the EU/EEA.

A possible WTO agreement will first and foremost focus on accessibility to the markets, reduction or conclusion of competitive advantages as for instance export subsidy and less specific (volume) support to dairy farmers. More use of measures independent of production is expected. This may imply measures linked to the degree of quality assurance on the farm, milk quality, a demand for fresher milk, organic products, a focus on safe food and health, season and regional products etc.

\section{Milk volume, price and market shares}

It is possible to imagine different scenaries for the development of milk volume, price and market shares, depending on how the Norwegian dairy industry will manage to compete in the future market:

1. The Norwegian dairy industry will not be able to compete on all product areas as today. We will have to reduce the milk volume and keep only the most profitable products. The quality must be high and our products will need some competitive advantages against imported goods. This will probably not be lower prices, but other added values the consumers are willing to pay for.

2. We maintain the milk volume on the stabilized level for the last years, that is approx. 1.500 mill. litres cow's milk. This implies a continuation of the positive trend obtained by the increase in sales of refined "special products", an increase that will compensate for the reduction in sales and market shares of "volume products". We will have to continue the development of the important $\mathrm{R} \& \mathrm{D}$ area as well as marketing, and we will have to introduce at least the same number of new products as today. The pressure on prices is expected to increase with an increase in imports and we will still need to focus on cost-effective production in all parts of the food chain. This, however, must not be at the expense of the quality of the products. This particular scenario presumes that the Norwegian agribusiness has found a way to compete by offering products with distinctive features, features that the consumers value. It is quite possible that the consumers will want to buy Norwegian food, because this will provide more safety regarding: ethical and 
environmental issues in connection with the production of food, traceability and an agriculture which attends to animal health and food safety in a better way than our competitors. Both consumers and the authorities want to sustain an agriculture and production of food in Norway.

3. The Norwegian dairy industry will be able to compete with the imports well enough to be able to increase the milk volume. This also implies that we have niches abroad for some profitable export products. The scenario has much in common with the second scenario, but in this third scenario one emphasizes the successful adjustments made regarding structure, cost-effective production, quality and profitable innovations in all sections. It also includes profitable export products.

\section{Quality in TINE BA's point of view}

Historically, milk quality has been defined as product related quality and quality measures have mainly been fat and protein content, sensory quality, number of bacteria and somatic cells. The latest years, more focus has been given to production related qualities like the product yield, functional and manufacturing properties and freshness.

Perception is also a part of the quality term. As consumers, we all demand safe, healthy and fresh food, but we are also aware of taste and price. The products must also be functional in a cooking perspective. There is an increased consumer focus on animal health and welfare and the possibility of tracing products back to the producer. The area of origin of different products is also of interest and may be used to provide the products with interesting background information (storytelling).

\section{Milk quality status in Norway today}

According to the "historically quality parameters" the quality of Norwegian milk is in the absolute front. TINE BA has several R\&D projects going on to sustain and even increase the quality of the milk on the farm level.

The development of the supplier's milk quality is positive (Table 1). This applies to the smell/taste, the total bacteria count and somatic cells. Since 1995 the use of antibiotics in the dairy farming has been reduced more than $50 \%$. If we compare the microbiological quality of the milk on the farm, Norwegian milk proves to be the best in the Nordic countries. The same applies to the cell-count. High quality is important as a basis for high quality products. A low cell-count will in addition contribute to improved qualities of the milk used for cheesemaking and improved cheese profit. 
Table 1. Quality development in Norwegian supplier's milk, 2001 to 2005

\begin{tabular}{|c|c|c|c|c|c|}
\hline \multirow{2}{*}{ Criteria } & \multicolumn{5}{|c|}{ Year } \\
\hline & 2001 & 2002 & 2003 & 2004 & 2005 \\
\hline \multicolumn{6}{|l|}{ Cow } \\
\hline bacteria, $\%$ of Elite milk ${ }^{1}$ & 96.04 & 96.43 & 97.52 & 97.67 & 97.70 \\
\hline organoleptic, $\%$ samples cl. $1^{2}$ & 97.47 & 97.68 & 98.07 & $98.96^{3}$ & $99.06^{3}$ \\
\hline Elite milk, \% of volume & 89.68 & 90.49 & 91.15 & 92.50 & 92.64 \\
\hline somatic cell, $\%$ of Elite milk ${ }^{4}$ & 93.20 & 94.08 & 93.89 & 94.11 & 93.95 \\
\hline protein, $\%$ & 3.21 & 3.26 & 3.26 & 3.29 & 3.32 \\
\hline fat, $\%$ & 4.04 & 4.00 & 4.01 & 4.03 & 4.07 \\
\hline \multicolumn{6}{|l|}{ Goat } \\
\hline bacteria, $\%$ of Elite milk ${ }^{1}$ & 90.58 & 8.53 & 91.42 & 91.63 & 93.29 \\
\hline organoleptic, $\%$ samples cl. $1^{2}$ & 89.74 & 91.05 & 93.08 & 95.88 & 96.04 \\
\hline Elite milk, \% of volume & 77.07 & 79.10 & 80.97 & 82.66 & 83.89 \\
\hline somatic cell, $\%$ of Elite milk ${ }^{4}$ & 81.13 & 84.90 & 83.81 & 85.56 & 86.03 \\
\hline protein, $\%$ & 2.71 & 2.96 & 2.94 & 2.96 & 2.99 \\
\hline fat, $\%$ & 3.55 & 3.53 & 3.58 & 3.66 & 3.76 \\
\hline
\end{tabular}

${ }^{1}$ the criteria for Elite milk concerning bacteria is below $20.000 \mathrm{cfu} \mathrm{mL}^{-1}$

${ }^{2}$ the criteria for Elite milk and cl. 1 milk concerning organoleptic analysis is now equal and below 1.3 mmole FFA $\mathrm{l}^{-1}$

${ }^{3}$ a shift in the analytical method took place in 2004 . The organoleptic test was replaced by the analysis of free fatty acids

${ }^{4}$ the criteria for Elite milk concerning somatic cell is below 230.000 for cow milk and 1.500 .000 cells $\mathrm{mL}^{-1}$ for goat milk

We also see a positive trend when it comes to the milk's content of fat and protein. Norway has traditionally had a lower chemical content in the supplier's milk than many other countries. This is mostly due to the farming system in Norway with a high share of forage and more extensive farming. Chemical content may also be influenced by systematic breeding, and breeding with the intention of obtaining a high content of protein has for long been one of several important breeding objectives for the breeding organization, GENO. The genetic potential for the protein percentage is however higher than the actual protein percentage because of our feeding arrangements.

The detection of antibiotics in Nordic milk is not a basis for comparison, because different methodologies are used in the different countries. For the same reason organoleptic quality is not suited as a basis for comparison. Free fatty acids have now replaced traditional organoleptic evaluation in Norway. Different methodology is also used in the detection of bacterial spores in the supplier's milk. Approximately 82 and $95 \%$ of the samples showed low content of respectively anaerobic spores (Clostridium) and aerobic spores (Bacillus cereus) in 2005. 
The zoonose status in Norway as in Sweden and Finland is good. The question of chemical contaminants is more difficult to answer. The documentation could have been better, nevertheless, we assume the situation to be good. The level of radioactivity varies from one year to another based on the local climatic conditions. The focus has been on cesium $\left({ }^{137} \mathrm{Cs}\right)$ since the Tsjernobyl accident in 1986.

\section{Norwegian milk's competitive edge}

NRF, Norwegian Red is a high producing dairy breed. GENO is a co-operative owned and managed by Norwegian dairy farmers. GENO's main aim is to breed the NRF in the most optimal way according to dairy farmers requests. The organization is responsible for both developing and managing breeding schemes, as well as reproductive techniques. The whole food chain is focused, from the NRF breed with special emphasis on production, health and fertility through feeding strategies of milk producing cows with the objective to produce high quality milk with special emphasis on protein and fat quality, and finally the dairy production. The following characteristics of Norwegian milk and NRF dairy breed (Table 2) can be given.

Table 2. Characteristics of Norwegian milk and NRF dairy breed

\begin{tabular}{ll}
\hline Statement & \\
\hline $\begin{array}{l}\text { Norwegian cows } \\
\text { are healthy }\end{array}$ & $\begin{array}{l}\text { We have very healthy and fertile cows. Our animal health situation is the best in } \\
\text { the world. This is partly due to breeding and partly due to combating of infectious } \\
\text { diseases. Minimal use of antibiotics combined with natural conditions. }\end{array}$ \\
$\begin{array}{l}\text { Breeding for } \\
\text { health and } \\
\text { fertility }\end{array}$ & $\begin{array}{l}\text { We are in a class of our own when it comes to breeding on health and fertility through } \\
\text { a unique registration and use of data including an animal health record. Health traits } \\
\text { and fertility have been included in the net merit index since the 1970s. }\end{array}$ \\
$\begin{array}{l}\text { Combating and } \\
\text { prevention of } \\
\text { infectious diseases }\end{array}$ & $\begin{array}{l}\text { For more than 100 years we have systematically worked for the prevention and } \\
\text { combating of serious infectious diseases (e.g., BSE, foot-and-mouth disease, } \\
\text { paratuberculosis) and less serious contagious diseases (e.g., ringworm and }\end{array}$ \\
$\begin{array}{l}\text { BVD). } \\
\text { Complete cow's }\end{array}$ & $\begin{array}{l}\text { Norway has a well developed "Kukontroll" (cow's inspection) with extensive } \\
\text { information on each individual. The information regarding health, veterinary } \\
\text { treatment and fertility is unique in Norway. About 95\% of the Norwegian dairy } \\
\text { farmers are affiliated with the "Kukontroll". }\end{array}$ \\
$\begin{array}{l}\text { Good hygiene on } \\
\text { supplier's milk }\end{array}$ & $\begin{array}{l}\text { Norwegian milk has for a number of years had very low bacterial content as } \\
\text { a result of hygiene focus, well-established cleaning procedures and efficient } \\
\text { cold storage units. Norwegian supplier's milk is also characterized by a very } \\
\text { low "cell-count". This shows that the milk delievered to the dairies is milk } \\
\text { from healthy cows. There has been a strong reduction in the medication of } \\
\text { Norwegian cows for the past 10 years (reduced by over 50\%). }\end{array}$ \\
\hline
\end{tabular}


Table 2. Continued

\begin{tabular}{|c|c|}
\hline Statement & \\
\hline $\begin{array}{l}\text { Distinctive } \\
\text { features of a } \\
\text { brief and intense } \\
\text { growing season }\end{array}$ & $\begin{array}{l}\text { Norway has a brief, but intense growing season with plenty of daylight. The country's } \\
\text { climate and topography are well suited for grass production and feed grain production. } \\
\text { Dairy farming is the most important contributor to value creation and also contributes } \\
\text { to sustaining the cultural landscape. The growth and fodder especially influences the } \\
\text { composition of the fatty acids in the milk. The fat is, however, important for the } \\
\text { colour, taste and health-related conditions. The Norwegian feeding regime gives a } \\
\text { relatively high content of polyunsaturated fatty acids. }\end{array}$ \\
\hline $\begin{array}{l}\text { Complete food } \\
\text { chain }\end{array}$ & $\begin{array}{l}\text { We have control of a complete food chain. This is an advantage where } \\
\text { traceability, food safety and innovation is concerned. }\end{array}$ \\
\hline Low pollution & National and local pollution is low. \\
\hline $\begin{array}{l}\text { Low-scale } \\
\text { farming }\end{array}$ & $\begin{array}{l}\text { Our structure reduces the danger of infection. Despite a development in this } \\
\text { field also in Norway, we will always maintain farming on a low-scale basis, } \\
\text { which distinguishes us from most other milk producing nations. }\end{array}$ \\
\hline
\end{tabular}

We also have some challenges we have to be aware of:

The Norwegian Norway is, geographically, a long country with dairy farming widely spread strategy for feeding all over the country. In a climatic perspective we are close to the limits for what is possible regarding the growing of grain and forage crops. Norwegian dairy farming is very important to the cultural landscape. Our climate protects us from many fungus infections and vermins and the use of pesticides is very restricted compared to many other countries.

We use a great deal of coarse fodder in dairy farming. During the winter season the feeding is unbalanced with extensive use of silage. Norway has far more occurrences of ketosis than our neighbouring countries.

Quality challenge The milk quality must be completely controlled all the way to the consumer. Natural conditions causes long transportation distances for milk and dairy products.

Chemical Low chemical content in the milk.

contaminants

in the milk

Radioactivity Radioactivity is a risk factor we supervise due to our geographical localization.

\section{Authority regulations}

The Ministry of Agriculture and Food is responsible for food and agricultural policymaking in Norway. The food policy aims to provide consumers with wholesome, high quality food products, and to ensure that the food production process is carried out with environmental, public health and animal welfare concerns in mind. 
The Norwegian Food Safety Authority are responsible for establishing regulations that ensure that no one will become ill by eating food in Norway. All producers or whole sellers of food are responsible to act in accordance with these regulations. Due to the EEA Agreement the Norwegian food legislation is to a large extent harmonized with the EU legislation. TINE BA has developed an advanced food safety system to be able to supply the market with safe food.

Human nutrition science has taken a major step forward from focus on the prevention of nutrient deficiencies to an emphasis on maintenance of good health and reduced risk of chronic diseases. Research has demonstrated that what and how much we eat affects growth, development and aging, and that dietary intake is linked to risks for development of diseases like cardiovascular disease, obesity, osteoporosis, cancer and diabetes. The cost of nutrition related diseases clearly points to the need of effective strategies to lower the cost of health care through the prevention of disease.

In the light of the results from research Norwegian health authorities make recommendations for dietary intake of different nutrients, and one of the most focused recommendation is reduced intake of fat, especially saturated fat. Milk fat has a relatively high content of saturated fat, and this has led to a negative consumer perception and a public health concern. The Norwegian health authorities and the consumers expect the food producers to be on the market with health promoting products, and to fulfil these expectations TINE BA emphasise research on and development of such products.

\section{Consumer requests}

"Traditional foods" are considered as one of the most important trends within the science of food. There is a growing interest abroad for the "Scandinavian kitchen". Our food traditions are regarded as exotic by foreigners because of our characteristic nature and culture.

"Food is fashion" was the catchy slogan through the mid/end 90's. The situation is however changed. The focus now is on tradition, retro, romance, nostalgia and safety. The Scandinavian consumers are among the most traditional and conservative when it comes to food and acceptance of new ingredients, new dishes and cooking methods.

These predictions are made by the Scandinavian trend institute, the Danish PEJ group (2006). The main focus now is on 4 so-called "trend universes"; 1. essential cooking, 2. the food doctor, 3. gourmet express, and 4. the local kitchen. According to the PEJ group these trends will make strong manifests in the near future.

In accordance with the trend report "Norsk Spisefakta" by Synovate MMI (2006), it may seem as we have had enough of foreign food, and that we prefer 
Norwegian food to a greater extent. Moreover, even more youths seem to take an interest in Norwegian food and Norwegian food traditions. The youth of today emphasizes the origin of the food, fresh raw materials - implying short distances, traceability and that the food itself has a story to tell.

However, there are several hurdles facing the small scale producers and the food industry. According to Jordana (2000) traditional foods are restricted by the current conditions in the market but they have good perspectives for growing in the future if some challenges are overcome. These challenges are: 1. communication (a traditional product is exotic in other markets and therefore has to be promoted); 2. legal protection of collective brands (insufficiently guaranteed in the different markets); 3. quality assurance (must be a priority objective, as in all the branded products); and 4. innovation.

In addition to the usual consumer drivers such as taste, convenience and presentation, food purchasing behaviour is also being driven by health-orientated factors. People are increasingly managing health through diet and many consumers report that specific health concerns influence their diet. Consumer awareness of diet-related diseases and the demand for health promoting products are challenges to the dairy industry. To meet these demands from both consumers and health authorities TINE BA has developed products low in fat and sugar, and products with added value. Examples of such products are low fat milk enriched with vitamin $\mathrm{D}$ and milk fermented with probiotic bacteria. More products with added value will be developed during the next years.

To develop products with improved nutritional value TINE BA also intend to change milk fat quality by lowering the content of saturated fat and increasing the content of unsaturated fat. Research projects conducted in cooperation with the Norwegian University of Life Sciences will reveal whether these changes are possible to achieve by feeding and breeding. Enhancing the health effects of naturally bioactive components by feeding or breeding and/or addition of bioactive components to dairy products is an important area for the future.

Additionally, consumer awareness is also to a greater extent focused on animal health and welfare which is reflected in an increasing interest for organic products. This has resulted in The Norwegian Government's aim that organic food production should be $15 \%$ of the total food production within 2015. It is a challenge to TINE BA to produce more organic milk.

\section{MILK QUALITY - A FUTURE APPROACH}

\section{Quality objectives for the future}

Increased prosperity and less physical activity have resulted in excessive obesity in the population. Obesity indicates that diet and lifestyle are inferior, 
but it even disposes for serious diseases like cardiovascular failures, diabetes and cancer.

The quality of food as a competetive preference is an important factor for the future. At the same time health promoting products, organic products, and functional food are in progress. Strictly relevant for the dairy industry are goals aiming to improve the milk quality in the light of the recent research into nutrition, to meet the demands from the authorities, and finally, to live up to consumer requests.

\section{The need to improve milk quality}

Milk represent one of the most important output from agriculture to the consumer. To stay competitive in a future market with the potential of increased import pressure and less loyal Norwegian consumers, TINE BA must maintain and improve competitiveness with respect to both product quality and productivity. The quality aspect of bovine milk are still questioned with respect to some health effects. Important for TINE and the Norwegian agriculture would be to find new methods to reduce certain fatty acids in the milk (e.g., saturated fatty acids). So fare neither animal breeders nor feeding specialists have the conclusions for assessing these parameters.

However, the fatty acid composition of milk seems to display genetic variability of the most common fatty acids in milk. There appears to be a potential for improving health benefits and reducing health risks by animal breeding as well as by modified feeding strategies.

We have several projects influencing milk quality both in TINE R\&D and in TINE advisory service for producers. Briefly presented are the goals of our main research projects related to milk quality as follows.

\section{Low fat-and low calorie products}

In collaboration with Campus Ås we have projects on developing low fatand low calorie products with good sensoric properties. These include technology aspects, consumer demands and sensory aspects.

\section{Functional food}

It seems possible to change the fatty acid composition by feeding and breeding, and in the future we believe we will be able to influence other parameters like genetic variants of proteins, bioactive peptides, immunoglobulins and important minor components in the milk and make "Natural Functional Food". We also have 
focus on addition of different bioactive components to our dairy products to make Functional Foods.

\section{Breeding}

In collaboration with Campus Ås (University of Life Sciences, Cigene, Matforsk - Norwegian Food Research Institute) Gilde BA and GENO, TINE BA takes part in a research project: "Functional genomics for optimized milk and meat quality".

The objective of the project is to improve the nutritive and sensory quality of milk and meat products and increase the competitiveness of the Norwegian agricultural sector, by combining modern biospectroscopy and functional genomics with the unique cattle recording systems in Norway.

The bovine genome sequence will be published in 2006. Norway has one of the world's best databases on the genetic history, productivity and health of individual cows and bulls. Together, these resources offer dramatically new tools for understanding and improving important aspects of animal health, production economy, nutritive and sensory quality of milk and meat products and consumer acceptability.

TINE uses an advanced and extensive quality control system for milk based on FT-IR spectroscopy, generating millions of informative, multi-channel measurements of milk per year. This project will try to extract much more information from these milk measurements by calibrating them for a number of new phenotypes (i.e. fatty acid profile). A variety of phenotypes will hopefully be obtained from these analyses.

New statistical tools will be used to determine the genetic component in FT-IR-based milk quality traits and to detect loci affecting the respective trait of interest. Interesting genes (mutations) will be pursued by new techniques within transcriptomics, proteomics and biospectroscopy at Campus Ås in an interdisciplinary effort.

\section{Feeding and farming systems}

There is strong evidence in the recent literature that it could be advantageous to reduce the content of saturated fatty acids in bovine milk such as lauric(C12:0), myristic- (C14:0) or palmitic acid (C16:0), and instead increase mono-and poly-unsaturated fatty acids (oleic acid 18:1 cis-9, $\alpha$-linoleic acid 18:3-n3), as well as the dominating conjugated linoleic acid (CLA), rumenic acid (18:2 cis-9 trans-11). The three saturated fatty acids increase the level of LDLcholesterol in serum (Kris-Etherton and Yu, 1997). High levels of serum LDLcholesterol is a strong risk factor for cardiovascular disease (Stamler et al., 1986). 
It is possible to improve the nutritional quality of the milk by means of feeding, in particular the pasture, but also by feeding indoors (Chillard et al., 2000; Walker et al., 2004). The feed also influences the sensorial and technological characteristics, so that it may be possible to create products the consumers will recognize by their distinctive features (Wetlesen et al., 2006). Characteristics related to emotions regarding the dairy farming are also part of the quality concept. Seeing cows at grass during the summer is for many people a positive experience, and they consider this milk "natural" to a greater extent than usual. This is best expressed by mountain dairy farming.

Several studies made by the University of Life Sciences, where TINE BA has participated, show that by increasing the intake of polyunsaturated fatty acids and by reducing the share of grain feed it is possible to alter the composition of fatty acids in the milk. The milk from cows given a low share of grain feed will contain more CLA and vaccenic acid, linoleic acid, $\alpha$-linoleic and oleic acid, and less of the saturated fatty acids (12:0, 14:0 and 16:0).

In collaboration with Campus Ås (University of Life Sciences, Matforsk Norwegian Food Research Institute, Bioforsk-Norwegian Institute for Agricultural and Environmental Research) we will concentrate on reducing the contents of medium- and long chained saturated fatty acids and on increasing the contents of mono- and polyunsaturated fatty acids (specially $\omega-3$ ) in the milk fat. In addition we will try to achieve a more stable content of iodine and selen. We will also study the taste and product quality of the milk and products made from this milk and focus on the place of origin and season.

\section{CONCLUSIONS}

Increasing globalization and reduced protective duties will cause more international trading. If we are to be competitive in the future we will have to offer extra values like for instance different quality aspects. We will to a considerable extent have to develop further added value and uniqueness preferred by the consumer for the specific products. This will probably include increased focus on place of origin and season. There also appears to be a potential for improving important health benefits and reducing health risks by animal breeding as well as by modified feeding strategies.

The fact that quality of Norwegian milk and NRF dairy breed is high must not be a hindrance for the work with improved product quality in TINE BA.

To fulfil consumer and public demands and requests TINE BA faces some challenges. We need insight into what the consumer expects from TINE BA and continuous information about and how to fulfil these requests. To succeed we need the right competence within the organization and in cooperation with external 
research institutes, to obtain knowledge about how to develop safe, healthy products with good taste. We also need knowledge about how to communicate the product advantages to the consumer.

\section{REFERENCES}

Chilliard Y., Ferlay A., Mansbridg R.M., Doreau M., 2000. Ruminant milk fat plasticity: nutritional control of saturated, polyunsaturated, trans and conjugated fatty acids. Ann. Zootech. 49, 181205

Jordana J., 2000. Traditional foods: challenges facing the European food industry. Food Res. Int. 33, 147-152

Kris-Etherton P.M., Yu S., 1997. Individual fatty acid effects on plasma lipids and lipoproteins: human studies. Amer. J. Clin. Nutr. 65, Suppl. 5, 1628-1644

PEJ Group, 2006. www.trendstore.dk. Herning (Denmark)

Stamler J., Wentworth D., Neaton J.D., 1986. Is relationship between serum cholesterol and risk of premature death from coronary hearth disease continuous and graded? JAMA 256, 2823-2828

Synovate MMI, 2006. "Norsk Spisefakta". Oslo (Norway)

Walker G.P., Dunshea F.R., Doyle P.T., 2004. Effects of nutrition and management on the production and composition of milk fat and protein: a review. Aust. J. Agr. Res. 55, 1009-1028

Wetlesen A., Borge G.I., Selmer-Olsen E., Abrahamsen R.K., 2006. Milk from cows on pasture - technological properties (in Norwegian). Meieriposten 4, 90-97 